\title{
Análise do conhecimento e comportamento de profissionais da área da saúde em relação ao protetor solar na cidade de Três Corações-MG
}

\author{
Andressa Gonçalves C. CAMPOS ${ }^{1 *}$, \\ Claudia Regina C.V. KAISER2*; \\ Alexandra Azevedo de CARVALHO3. \\ Jeanete MOUSSA
}

\begin{abstract}
${ }^{1}$ Graduada de Tecnologia em Cosmetologia e Estetica/UNINCOR
2 Graduada deTecnologia em Cosmetologia e Estetica/UNINCOR

3 Fisioterapeuta, Mestre em Educação, Professora e Coordenadora do Curso de Cosmetologia e Estética/UNINCOROrientadora do trabalho.alexandrafisio2004@yahoo.com.br

${ }^{4}$ Biomédica, Técnica em Estética Facial e Corporal, Mestre em Educação, Doutora em Reabilitação pela UNIFESP, Professora e Coordenadora do Curso de Pós-Graduação em Estética Integral/ Universidade Gama Filho - orientadora do trabalho. contato.especiariascosmeticas@gmail.com

* As autoras contribuíram igualmente no desenvolvimento do trabalho.
\end{abstract}

\section{Recebido em: 15/05/2013 - Aprovado em: 15/07/2013 - Disponibilizado em: 15/08/2013}

\section{RESUMO}

O Sol é essencial para a vida na Terra e seus efeitos sobre o homem dependem das características individuais da pele exposta, intensidade, frequência e tempo de exposição. Estes efeitos trazem benefícios ao ser humano, como sensação de bem-estar físico e mental, tratamento de patologias, síntese de vitamina D. Porém, a radiação solar também pode causar prejuízos ao organismo, caso não se tome os devidos cuidados quanto à dose de radiação solar recebida. Com o crescente conhecimento a respeito das radiações ficou evidente que a pele precisaria ser protegida de toda faixa UVA/UVB/UVC para reduzir o risco de câncer de pele e outras patologias associadas, causadas por exposição ao sol. Um protetor solar eficiente deve prevenir não apenas uma possível queimadura, mas também reduzir o acúmulo de todas as lesões induzidas pela radiação UV. Imagina-se que os profissionais da área da saúde possuam conhecimento sobre estes efeitos nocivos a saúde, e sendo assim, atuem de maneira a evitar tais danos. Dessa forma, o objetivo dessa pesquisa foi verificar o quanto o conhecimento influencia no comportamento dos profissionais da área da saúde em relação ao uso de fotoprotetor. O presente estudo foi desenvolvido através da aplicação de 362 questionários, o que representa $30 \%$ dos profissionais da área da saúde que atuam no município de Três Corações-MG. O resultado da pesquisa salienta que estes profissionais possuem conhecimentos sobre o tema e reconhece os riscos inerentes a radiação solar sem fotoproteção, porém se comportam de maneira diferente, pois a maioria não utilizam fotoprotetores.

Palavras Chave: Sol. Radiação Ultravioleta. Fotoprotetor. Conhecimento. Comportamento.

\section{ABSTRACT}

The sun is essential for life on Earth and its effects on man depend on the individual characteristics of the exposed skin, intensity, frequency and duration of exposure. These effects are beneficial to humans, such as sense of well-being and mental health, treatment of diseases, synthesis of vitamin D. However, solar radiation can also cause damage to the body if not take proper care regarding the dose of radiation received. With increasing knowledge about the radiation was evident that the skin need to be protected from all band UVA / UVB / UVC to reduce the risk of skin cancer and other disorders caused by sun exposure. An effective sunscreen should not only prevent a possible burn, but also reduce the accumulation of all lesions induced by UV radiation. It is thought that health professionals have knowledge about these harmful effects to health and well being, act so as to prevent such damage. Thus, the objective of this research was to investigate how knowledge influences the behavior of health professionals regarding the use of sunscreens. The present study was developed through the application of 362 questionnaires, representing $30 \%$ of health professionals who work in the city of Hearts Three-MG. The search result emphasizes that these professionals possess knowledge on the subject and recognizes the risks inherent to solar radiation without sunscreen, but behave differently, since most do not use sunscreen.

Keywords: Sun. Ultraviolet Radiation. Sunscreen. Knowledge. Behavior.

\section{INTRODUÇÃO}

Nas últimas décadas as pessoas têm se exposto muito mais ao sol, por vários motivos. A exposição à radiação ultravioleta (RUV) solar induz uma sensação de bem- estar e quando limitada, traz benefícios comprovados, como a síntese de pró-vitamina $\mathrm{D}_{3}$, o ajuste do relógio biológico humano e até o controle de sintomas depressivos. Contudo estes efeitos podem ser conseguidos com 
mínimas exposições solares.( BATISTUZZO, C.C, 1999)

Quando em excesso a RUV pode ser responsável por muitos efeitos biológicos indesejados. Exposição solar, principalmente em horários de maior intensidade de raios ultravioleta (UV), determina diversas alterações e riscos cutâneos, desde o surgimento de lesões degenerativas, acelerando o processo de envelhecimento, até o maior deles que é a definida influência sobre o desenvolvimento de carcinomas de pele (CARESTIATO, J.C, 2003). Isso se baseia no fato que a RUV, especialmente no espectro de 290-320nm (UVB), é capaz de atuar em vários estágios da carcinogênese, da iniciação à promoção e progressão dos tumores (GERVASI, V.S,1999).

$\mathrm{O}$ espectro solar que atinge a superfície terrestre é formado predominantemente por radiações ultravioletas (100-400 nm), visíveis (400-800 $\mathrm{nm}$ ) e infravermelhas (acima de $800 \mathrm{~nm}$ ). Nosso organismo percebe a presença destas radiações do espectro solar de diferentes formas. (MANSUR, J. S.; BREDER, M. N.; MANSUR, M. C. A.; AZULAY, R. D, 1996)

A radiação infravermelha (IV) é percebida sob a forma de calor, a radiação visível (Vis) através das diferentes cores detectadas pelo sistema óptico e a radiação ultravioleta (UV) através de reações fotoquímicas. Tais reações podem estimular a produção de melanina cuja manifestação é visível sob a forma de bronzeamento da pele, ou pode levar desde a produção de simples inflamações até graves queimaduras. Também há a possibilidade de ocorrerem mutações genéticas e comportamentos anormais das células, cuja frequência tem aumentado nos últimos anos (NASSER, Nilton; AZULAY, Rubem David., 2008).

A energia da radiação solar aumenta com a redução do comprimento de onda, assim a radiação UV é a de menor comprimento de onda e, consequentemente, a mais energética, mais propensa a induzir reações fotoquímicas (PETRY, V.; REY, M. C. W.; PIVA, D.; FISCHER, A. C.; WELTER, E. Q.; WEBER, M. B.; BONAMIGO, R. R, 2008).

Outra consideração importante diz respeito à capacidade desta radiação permear a estrutura da pele. A radiação UV de energia menor penetra mais profundamente na pele e, ao atingir a derme, é responsável pelo fotoenvelhecimento. A faixa da radiação UV (100 a $400 \mathrm{~nm}$ ) pode ser dividida em UVA (320 a $400 \mathrm{~nm}$ ) que frequentemente não causa eritema. Dependendo da pele e da intensidade da radiação recebida, o eritema causado é mínimo. Quando comparada à radiação UVB, sua capacidade em induzir eritema na pele humana é aproximadamente mil vezes menor, porém penetra mais profundamente na derme. Induz pigmentação da pele promovendo o bronzeamento por meio do escurecimento da melanina pela fotoxidação da leucomelanina, localizada nas células das camadas externas da epiderme. Histologicamente, causa danos 
ao sistema vascular periférico e induz o câncer de pele, dependendo do tipo de pele e do tempo, frequência e intensidade de exposição. Também pode agir de maneira indireta, formandos radicais livres (GERVASI, V.S., 1999).

A UVB (280 a $320 \mathrm{~nm})$ atinge toda a superfície terrestre após atravessar a atmosfera. Possui alta energia e, com grande frequência, ocasiona queimaduras solares. Também induz o bronzeamento da pele, sendo responsável pela transformação do ergosterol epidérmico em vitamina $\mathrm{D}$, e causa o envelhecimento precoce das células (MARTINS, J.L.S., 1993). A exposição frequente e intensa à radiação UVB pode causar lesões no DNA, além de suprimir a resposta imunológica da pele. Desta forma, além de aumentar o risco de mutações fatais, manifestado sob a forma de câncer de pele, sua atividade reduz a chance de uma célula maligna ser reconhecida e destruída pelo organismo (OLIVEIRA FILHO, J., 2001).

A radiação UVC (100 a $280 \mathrm{~nm})$ é portadora de elevadas energias, característica que a torna extremamente lesiva aos seres vivos. Devido a fatores ambientais, a redução na camada de ozônio tem levado a um aumento da radiação UVB e UVC na superfície da Terra, ocasionando maior incidência de queimaduras e, consequentemente, câncer de pele (NASSER, Nilton; AZULAY, Rubem David. 2008)

Com o crescente conhecimento a respeito das radiações ficou evidente que a pele precisaria ser protegida de toda faixa UVA/UVB/UVC para reduzir o risco de câncer de pele causado por exposição ao sol. Um protetor solar eficiente deve prevenir não apenas uma possível queimadura, mas também reduzir o acúmulo de todas as lesões induzidas pela radiação UV, que podem aumentar o risco de alterações fatais (OLIVEIRA FILHO, J., 2001).

Proteger a pele frente às manifestações produzidas pela radiação UV significa converter a energia desta em outra forma de energia e ter garantias de que esta outra forma não seja prejudicial à pele (OLIVEIRA FILHO, J., 2001). Os filtros UV empregados em formulações de protetores solares necessitam ser química e fotoquimicamente inertes. Existem duas classes de filtros solares: orgânicos e inorgânicos, classificados rotineira e respectivamente como filtros de efeito químico e físico.

Os protetores solares físicos dissipam ou refletem a radiação UV e raramente estão associados com reações alérgicas. Estes dissipam a variação mais ampla da luz incluindo o espectro UV, visível e infravermelho, e estão recomendados para uso especialmente quando a exposição ao sol intenso. Dióxido de titânio, óxido de magnésio, de ferro e zinco são os ingredientes primários nos protetores solares físicos. Os filtros químicos geralmente são combinados aos filtros físicos ou entre si para formar produtos com alto FPS que podem ser utilizados durante tempos de exposição 
significativa ao sol. Estes absorvem a radiação UV, esta deve ser dissipada na forma de calor ou de luz ou ser utilizada na em alguma reação química. Isso pode levar a criação de espécies reativas de oxigênio ou fotoprodutos que podem atacar outros químicos da formulação; se absorvido pode atacar a pele propriamente dita (RIBEIRO, R. P.; SANTOS, V. M.; MEDEIROS, E. C.; SILVA, V. A.; VOLPATO, N.M.;GARCIA, 2004). Esta confirmaria a tese de que os protetores solares possam causar câncer, devido as reações químicas consequentes. Nos filtros orgânicos temos a presença de compostos orgânicos e nos inorgânicos temos a presença de óxidos metálicos. Geralmente, os compostos orgânicos protegem a pele pela absorção da radiação e os inorgânicos, pela reflexão da radiação (BRASIL. Ministério da

Saúde. Agência Nacional de Vigilância Sanitária, 2006)

Os filtros orgânicos são formados por moléculas capazes de absorver a radiação UV (alta energia) e transformá-la em radiações com energias menores e inofensivas ao ser humano. Os protetores devem apresentar características como ser atóxico; não ser sensibilizante, irritante ou mutagênico; não ser volátil; possuir características solúveis apropriadas; não ser absorvido pela pele; não alterar sua cor; não manchar a pele e vestimentas; ser incolor; ser compatível com a formulação e material de acondicionamento e, ser estável no produto final (FLOR, J.; DAVOLOS, M. R.; CORREA, M. A, 2007)
A eficácia dos filtros é dependente da sua capacidade de absorção da energia radiante, que é proporcional à concentração dos compostos absorvedores e/ou refletores de radiação eletromagnética que o compõe, intervalo de absorção e comprimento de onda onde ocorre absorção máxima. A associação de diferentes filtros, químicos e físicos, em formulações é um recurso para melhorar a eficácia e potencializar o FPS (PAOLA, 1998).

É preciso utilizar protetores físicos como chapéus, óculos, roupas de mangas compridas a fim de diminuir as áreas expostas. Muitos especialistas não indicam a utilização de protetores solares em bebês com menos de 6 meses devido a alta sensibilidade da pele dos mesmos. O que se indica é o uso de protetores físicos e aderir a roupas que possuam foto proteção. Já existem no mercado roupas com foto proteção, inclusive para bebês, porém seu alto custo dificulta a aceitação populacional (NASCIMENTO, M.S., 2008).

Os FPS variam de 8 a 100, sendo que determinar a numeração correta a cada fototipo de pele para correto uso de protetor solar se faz importante. As variações entre estas numerações tem pouca diferença na mensuração de fotoproteção, porém, em determinados casos, esta diferença mínima se torna relevante, tendo em vista que os efeitos da radiação solar nocivos, exposto a um paciente que já seja portador de determinada patologia, se torna de vital importância 
(FLOR, J.; DAVOLOS, M. R.; CORREA, M. A, 2007)

Imagina-se que os profissionais da área da saúde possuam conhecimento sobre estes efeitos nocivos da radiação ultravioleta no organismo humano, e sendo assim, atuem de maneira a evitar tais danos. Acredita-se que à medida que aumenta o nível de escolaridade, do ensino fundamental ao superior, eleva-se o percentual de indivíduos conhecedores dos danos ou conseqüências da fotoexposição (HORA, C.; BATISTA, C. V. C.; GUIMARÃES, P. B.; SIQUEIRA, R.; MARTINS, S., 2003).

Sabe-se que as a maioria da população brasileira não possui boas condições sócioeconômicas, desta forma o acesso aos serviços de saúde, atendimentos e demais produtos foge da realidade de muitos. O acesso às consultas dermatológicas, por exemplo, ainda é restrito a uma pequena parcela da população no país; sendo assim, é importante que os demais profissionais da área de saúde detenham o conhecimento sobre os efeitos danosos do sol e sobre os meios de prevenção das doenças de pele e em especial o câncer cutâneo. Os profissionais de saúde devem assumir este importante papel e fornecer orientações aos pacientes a respeito da fotoproteção e dos exames e inspeções de saúde a fim de detectar lesões precursoras de neoplasias, bem como aplicarem esses conhecimentos em benefício próprio. Muitos autores acreditam que o aconselhamento adequado aos pacientes por parte dos profissionais da saúde pode aumentar a freqüência da adoção de medidas preventivas (CANDEIAS, NMF, 1997).

Dessa forma, o objetivo dessa pesquisa foi verificar o quanto o conhecimento influencia no comportamento dos profissionais da área da saúde em relação ao uso de protetor solar. O propósito é analisar se o conhecimento influencia e altera o comportamento sobre o assunto, pois pressupõem que para quem cuida do outro na área saúde, primeiramente é preciso realizar o auto-cuidado.

\section{METODOLOGIA}

Tipo de Estudo - Trata-se de pesquisa exploratória com abordagem qualiquantitativa.

Local do estudo - O estudo foi desenvolvido na cidade de Três Corações, MG

População e Amostra - Profissionais da área da saúde da cidade de Três Corações, MG, que se dispuseram a participar da pesquisa de maneira voluntária. Foram aplicados 362 questionários, o que representou $30 \%$ dos profissionais cadastrados no município no ano de 2012, conforme dados informados pela Prefeitura Municipal de Três Corações, MG. Foi solicitado o consentimento dos profissionais que participaram da pesquisa

Procedimento de coleta de dados - Foi elaborado um questionário com perguntas referentes ao conhecimento e comportamento em relação ao sol, radiação solar,doenças 
associadas a exposição solar e ao uso de fotoprotetor. Os resultados foram contabilizados e expressos em gráfico

\section{RESULTADOS E DISCUSSÃO}

Gráfico 1 - Utilizam protetor solar diariamente

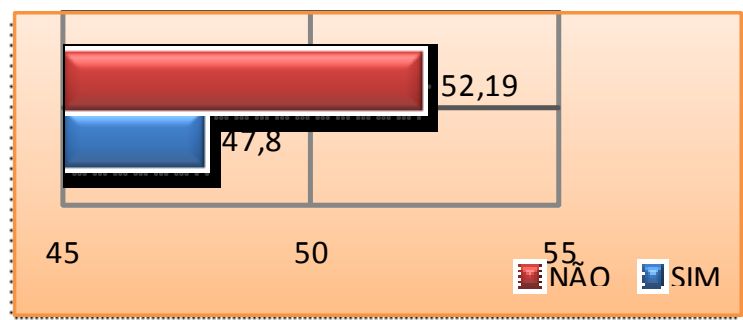

Fonte: os autores

O gráfico 1 demonstra que a diferença entre os dois valores é de significância, onde devemos observar que apesar dos profissionais serem da área da saúde e se pressupor que possuem informações o bastante para que utilizem o filtro solar, isto não ocorre com tanta freqüência quanto se deveria. Os filtros solares tornaram-se indispensáveis, sendo de extrema importância a sua utilização a exposição prolongada à radiação solar pode provocar danos irreparáveis desde queimaduras e aumentando substancialmente o risco de se desenvolver câncer, além de levar ao envelhecimento precoce. (MAIO, de Mauricio, 2009). O hábito do uso de proteção solar é de vital importância, havendo a necessidade de associar o uso de protetor solar com saúde.
Gráfico 2 - Motivos pelos quais não utilizam protetor solar

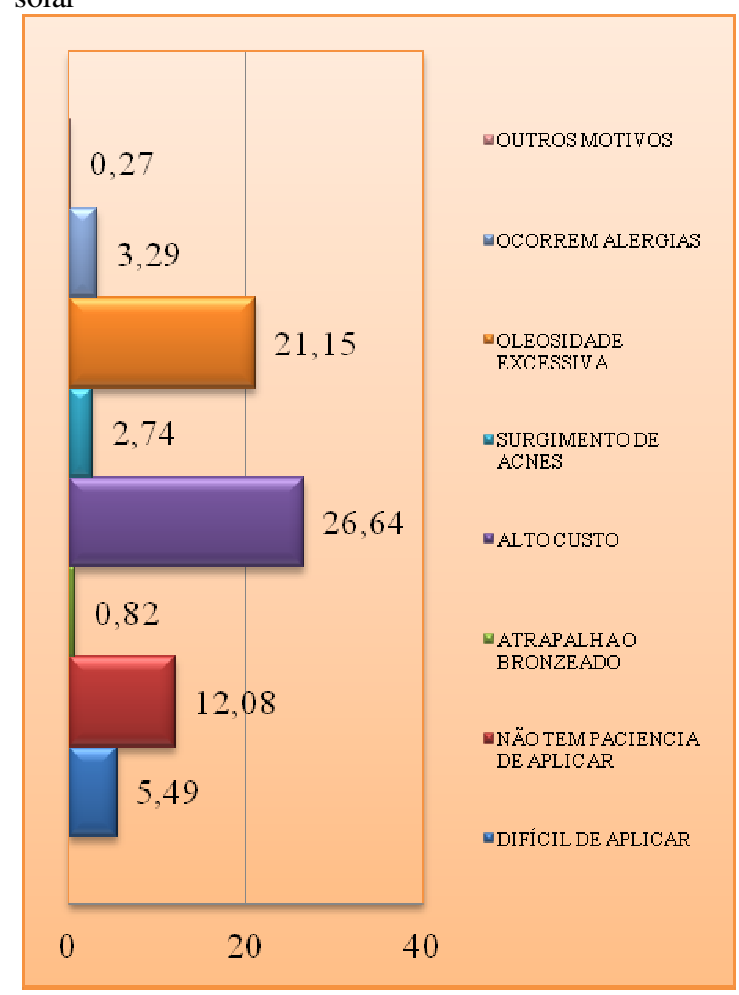

Fonte: os autores

O gráfico 2 aponta possíveis motivos que levam os profissionais da área da saúde a não utilizar o filtro solar. $\mathrm{O}$ alto custo, seguido da oleosidade excessiva do produto, nos leva a crer que a indústria de filtros solares necessita reduzir os preços e não se basear em FPS para calcular o preço final dos produtos. Cabe ainda ressaltar a má informação dos entrevistados, tendo em vista que se soubessem o tipo de veículo correto para cada tipo de pele, a oleosidade deste não seria um problema. $\mathrm{O}$ mercado Brasileiro de proteção solar já é o maior do mundo havendo uma diversidade de marcas, levando uma gama de opções aos seus consumidores, tanto de qualidade quanto na questão de preços. (GALENA,2007.) 


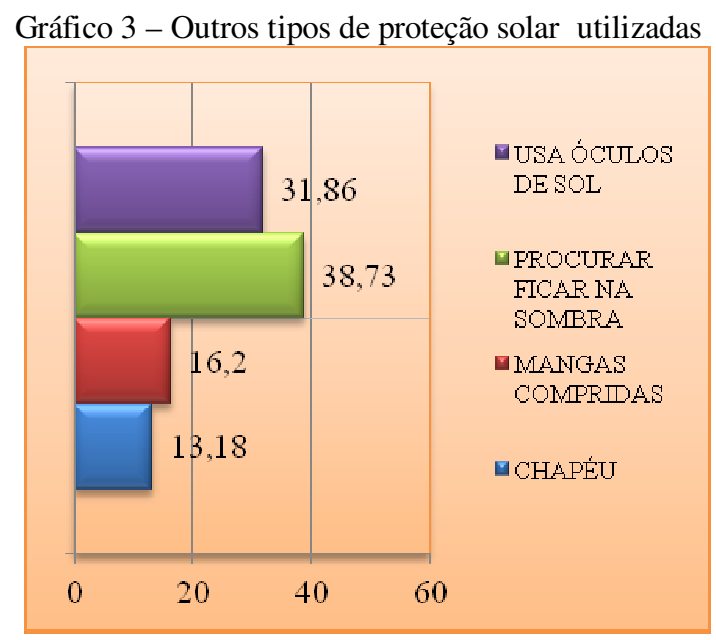

Fonte: os autores

O gráfico 3 mostra que a maioria da população, para se proteger da radiação solar, procura ficar a sombra e a utilizar óculos de sol, sendo estes muitas vezes inadequados ao uso. Os óculos utilizados (de acordo com relatos dos entrevistados) são ineficientes em relação à radiação UV, sendo comprados em camelôs ou ainda em lojas quaisquer, mostrando assim a despreocupação dos entrevistados. Os chapéus, bonés e óculos com lentes que bloqueiam os raios ultravioletas são alguns dos assim chamados protetores físicos aliados importantes na proteção solar. Tecidos com alta tecnologia já são apresentados no mercado com componentes que agem como protetores, permitindo a fabricação de roupas que bloqueiam os raios ultravioletas. (MAIO, de Maurício,2009).

Gráfico 4 - Aplicam protetor solar antes da exposição ao sol

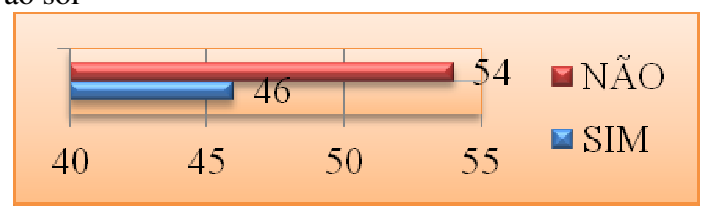

Fonte: os autores
Nota-se no gráfico 4 que a importância da aplicação ainda não está bem definida para os profissionais da área da saúde. NORA, Adelar Bocches, et al (2004), corroboram o trabalho ao constatarem que $76,92 \%$ dos indivíduos analisados em seu estudo, não usam protetor solar devido a falta de hábito ou esquecimento, mesmo tendo conhecimento da importância da fotoproteção. É fundamental o hábito diário quanto ao uso do protetor solar antes de se expor ao sol, apesar de muitas informações pela mídia ainda vemos a grande dificuldade quanto a conscientização do uso do protetor. A reaplicação do foto protetor também é importante. Normalmente, a recomendação de aplicar a cada 2 a 3 horas mão é considerada (FLOR, J.; DAVOLOS, M. R.; CORREA, M. A, 2007).

Gráfico 5 - Já notaram vermelhidão na pele ou queimadura após exposição solar

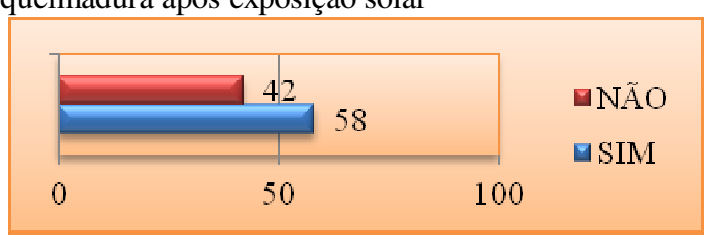

Fonte: os autores

O gráfico 5 demonstra que a maioria da população já apresentou algum tipo de vermelhidão cutânea, o que também acaba alarmando ainda mais sobre as questões de permanecer exposto ao sol por um longo tempo sem o uso de fotoprotetor. Fazendo um paralelo ao gráfico 3 onde observa-se que a maioria dos participantes da pesquisa $(38,73 \%)$ relataram ficar à sombra para evitar 
os danos da radiação, porém essa atitude não evita os danos solares. A radiação é incidente mesmo quando à sombra, pois ocorre a reflexão dos raios que acabam sendo nocivos ((MARTINS, J.L.S., 1993)

Gráfico 6: Alguém na família já apresentou câncer de pele

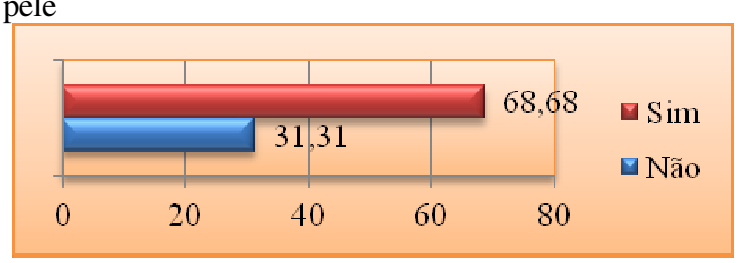

Fonte: os autores

Nota-se no gráfico 6 que este dado é alarmante, visto que as conseqüências do acúmulo da radiação absorvida pelo organismo humano, tendem a aparecer tardiamente de maneira a provocar lesões graves, principalmente na pele (OLIVEIRA FILHO, J., 2001)

Gráfico 7 - Já receberam informações sobre o assunto de fotoproteção

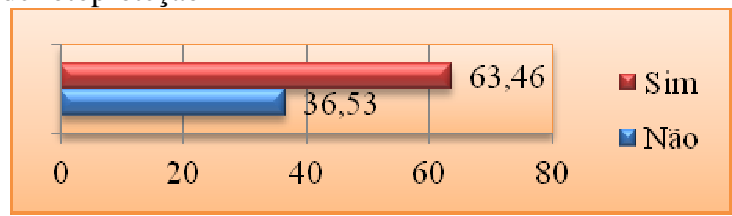

Fonte: os autores

No gráfico 7, 63,46\% dos participantes da pesquisa relataram que recebeu informações de significância sobre a fotoproteção, mas isso demonstra que não é suficiente para que eles façam uso constante do protetor solar, como é ilustrado no gráfico 4. Isso demonstra a necessidade de estudos e divulgação sobre o assunto. O que se nota é uma divulgação, principalmente da mídia sobre a fotoproteção apenas no período de verão, o pode acabar passando para a população que este é o único período em que se faz necessário o uso de proteção solar. Nas demais estações do ano também ha forte incidência de raios UV no planeta (NASSER, Nilton; AZULAY, Rubem David, 2008)

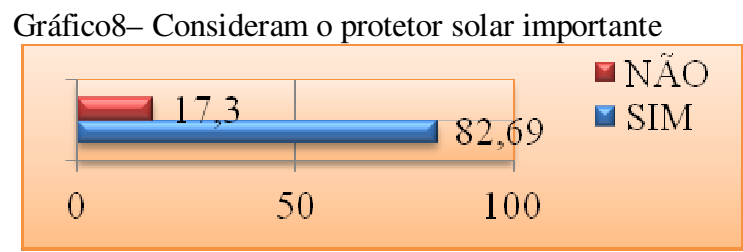

Fonte: os autores

Nota-se no gráfico 8 , que os participantes da pesquisa consideram o protetor solar importante, porém não realizam a aplicação devido a altos custos, consistência do produto, falta de hábito, ou seja, o comportamento influencia de maneira direta no não uso de protetor solar, mesmo sabendo das consequências disso (NORA, Adelar Bocches, et al, 2004).

\section{CONCLUSÃO}

$\mathrm{O}$ resultado da pesquisa salienta que estes profissionais possuem conhecimentos sobre o tema e reconhecem os riscos inerentes a radiação solar sem fotoproteção, porém mesmo assim se comportam de maneira diferente, não sendo usuários de fotoprotetores, como mostrou a pesquisa onde $52,19 \%$ dos entrevistados não utilizam o filtro solar, mesmo quando $82,69 \%$ apontam que o filtro solar é importante para a prevenção de 
danos actínicos e tissulares e 68,68\% dos entrevistados afirmam que alguém da família já apresentou câncer de pele. Esta pesquisa tem relevância por trazer dados científicos que demonstram o quanto apenas o conhecimento não é primordial para alterar o comportamento em relação ao uso do protetor solar, sendo necessário investimento em campanhas educacionais e inclusão do tema nos setores de saúde pública.

\section{REFERÊNCIAS BIBLIOGRÁFICAS}

BATISTUZZO, C.C. A proteção para tomar sol na medida certa. Revista

Farmacêutica Kairos, v. 3, n. 1, p. 26-28. $1999 \mathrm{a}$

BRASIL. Ministério da Saúde. Agência

Nacional de Vigilância Sanitária. Resolução $\mathrm{n}^{\circ} 47$, de 16 de março de 2006. Regulamento técnico "Lista de filtros ultravioletas permitidos para produtos de higiene pessoal, cosméticos e perfumes”. Disponível em $<$ http://elegis.anvisa.gov.br/leisref/public/sho wAct.php?id=21264\&word=>. Acesso em 04 jun. 2012

BRASIL. Ministério da Saúde. Agência Nacional de Vigilância Sanitária. Resolução $\mathrm{n}^{\circ} 237$, de 22 de agosto de 2002.

Regulamento técnico sobre protetores solares em cosméticos. Disponível em $<$ http://elegis.bvs.br/leisref/public/showAct.p hp?id=267>.

Acesso em 04 jun. 2012
CANDEIAS, NMF. Conceitos de educação e de promoção em saúde: mudanças individuais e mudanças organizacionais. Rev Saúde

Pública = J Public Health. 1997;31(2):209-

13.

CARESTIATO, J.C. Câncer e meio ambiente.

Rev. Bras. Farm., v. 84,n.2, p. 55-60, 2003.

FLOR, J.; DAVOLOS, M. R.; CORREA, M.

A. Protetores Solares. Quim.Nova,

Araraquara, v.30, n.1, p.153-158, 2007.

GALENA. Filtros solares. Informe

Científico Galena para profissionais de

saúde,v.1, p. 1-14, 2007.

GERVASI, V.S. Efeitos Cutâneos das

Radiações Ultravioleta. Revista de

Cosmiatria \& Estética, p.25-30, jul/ago/set , 1999.

HORA, Clarissa da ET AL. Avaliação do conhecimento quanto a prevenção do câncer da pele e sua relação com exposição solar em frequentadores de academia de ginástica, em Recife. An.Bras.Dermatol. Rio de Janeiro, v.78, n6, p. 693-701, Nov/dez 2003

MAIO, de Maurício. Tratado de Medicina

Estética. Editora Rocca, São Paulo: 2004

MANSUR, J. S.; BREDER, M. N.;

MANSUR, M. C. A.; AZULAY, R. D. 
Radiações ultravioletas: Prevenção dos seus efeitos maléficos. Anais Brasileiros de Dermatologia, v.61, n.2, p.73-78, 1996a. MARTINS, J.L.S.Avaliação da eficácia dos bronzeadores contendo filtros solares. Saúde - UFSM, v.19 (1-2), p. 23-25, 1993.

NASCIMENTO, M.S. Proteção solar: mercado quente. Revista de Negócios da indústria da Beleza - Edição temática: Proteção Solar, n. 7, p.7-8, 2008.

NASSER, Nilton; AZULAY, Rubem David. Prevenção do câncer da pele e fatores ambientais. In: NEVES, K. Sol e origem da radiação eletromagnética. Revista de Negócios da indústria da Beleza - Edição temática: Proteção Solar, n. 7, p.10-13, 2008a.

NORA, Adelar Bocches, et al. Frequência de aconselhamento para prevenção de câncer da pele entre as diversas especialidades médicas em Caxias do Sul. An. Bras. Dermatol.,Rio de Janeiro, v.79, n.2, p. 149-155, mar/abr. 2004

OLIVEIRA FILHO, J. Estrutura e função da pele. In: CUCÉ, L.C.; NETO, C.F.

Manual de dermatologia. 2 a edição. São

Paulo: Atheneu, 2001
PETRY, V.; REY, M. C. W.; PIVA, D.; FISCHER, A. C.; WELTER, E. Q.; WEBER, M. B.; BONAMIGO, R. R. Exposição solar, fotoproteção e câncer da pele: comparação entre os conhecimentos auto-referidos por médicos residentes em pediatria $\mathrm{e}$ dermatologia. Revista da AMRIGS, Porto Alegre, v. 52, n. 2, p. 93-96, abr.-jun. 2008.

Disponível em:< http://www.amrigs.org.br/revista/52-02/07170-exposi\%E7\%E3o_solar.pdf $>$. Acessado em: 3 jun. 2012.

RIBEIRO, R. P.; SANTOS, V. M.; MEDEIROS, E. C.; SILVA, V. A.; VOLPATO, N.M.;GARCIA, S. Avaliação do Fator de Proteção Solar (FPS) in vitro de produtos comerciais e em fase de desenvolvimento. Infarma, v.16, n.7-8, p.8588, 2004.

PAOLA, M. V. R. V. Importância da Fotoproteção. Revista de Cosmiatria \&

Estética, p.5-7, out-nov-dez, 1999. 